\title{
Corrigendum: Genomic profiling of pelvic genital type leiomyosarcoma in a woman with a germline CHEK2: c.1100delC mutation and a concomitant diagnosis of metastatic invasive ductal breast carcinoma
}

My Linh Thibodeau, Caralyn Reisle, Eric Zhao, Lee Ann Martin, Yazeed Alwelaie, Karen L. Mungall, Carolyn Ch'ng, Ruth Thomas, Tony Ng, Stephen Yip, Howard Lim, Sophie Sun, Sean S. Young, Aly Karsan, Yongjun Zhao, Andrew J. Mungall, Richard A. Moore, Daniel Renouf, Karen Gelmon, Yussanne P. Ma, Malcolm Hayes, Janessa Laskin, Marco A. Marra, Kasmintan A. Schrader, and Steven J.M. Jones

In the above-mentioned article, a co-corresponding author's e-mail address was incorrect. The correct e-mail address for K.A. Schrader is ischrader@bccancer.bc.ca and has been corrected in the current version of the article.

doi: $10.1101 / \mathrm{mcs} .0003327$ 


\section{COLD SPRING HARBOR Molecular Case Studies}

\section{Corrigendum: Genomic profiling of pelvic genital type leiomyosarcoma in a woman with a germline CHEK2:c.1100delC mutation and a concomitant diagnosis of metastatic invasive ductal breast carcinoma}

My Linh Thibodeau, Caralyn Reisle, Eric Zhao, et al.

Cold Spring Harb Mol Case Stud 2018, 4: a003327

Access the most recent version at doi: $10.1101 /$ mcs.a003327

\section{License}

Email Alerting Receive free email alerts when new articles cite this article - sign up in the box at the Service top right corner of the article or click here. 